San Jose State University

SJSU ScholarWorks

$5-2019$

\title{
Identifying Predictors of Airway Complications in Conscious Sedation Procedures
}

\author{
Rosemary Bray \\ California State University, Northern California Consortium Doctor of Nursing Practice
}

Follow this and additional works at: https://scholarworks.sjsu.edu/etd_doctoral

Part of the Perioperative, Operating Room and Surgical Nursing Commons

\section{Recommended Citation}

Bray, Rosemary, "Identifying Predictors of Airway Complications in Conscious Sedation Procedures" (2019). Doctoral Projects. 115.

DOI: https://doi.org/10.31979/etd.c8tt-5feh

https://scholarworks.sjsu.edu/etd_doctoral/115

This Doctoral Project is brought to you for free and open access by the Master's Theses and Graduate Research at SJSU ScholarWorks. It has been accepted for inclusion in Doctoral Projects by an authorized administrator of SJSU ScholarWorks. For more information, please contact scholarworks@sjsu.edu. 


\section{ABSTRACT \\ IDENTIFYING PREDICTORS OF AIRWAY COMPLICATIONS IN CONSCIOUS SEDATION PROCEDURES}

Problem: Conscious sedation procedures are complicated by unanticipated airway compromise and obstruction. The STOP-Bang questionnaire (University of Toronto, 2012) is a validated obstructive sleep apnea (OSA) screening questionnaire used as a pre-procedure evaluation tool to assess a patient's risk for OSA. There are four verifiable, objective questions and four subjective questions. This study examines to what extent the STOP-Bang score question variables reliably predict airway complications during conscious sedation procedures. Method: The method was a retrospective review of data from the electronic medical record (EMR) of patients who had conscious sedation for endoscopy procedures. The individual questions of the STOP-Bang questionnaire were manually collected as independent predictor variables. Physiologic signs of airway compromise and documented airway maneuvers to relieve airway obstruction were collected as dependent outcome variables. Logistic regression analysis was preformed to predict outcome severity based on individual and total STOP-Bang questionnaire scores.

Results: A STOP-Bang threshold score of greater than 5, indicating a high risk for OSA, was determined to be predictive of a heart rate change greater than $10 \%$ from baseline during the procedure $(\mathrm{p}=.021)$ and periods of apnea of (respiratory rate less than or equal to 8 seconds) $(\mathrm{p}=.038)$, indicating airway compromise. The STOP-Bang threshold score of greater than 5 was statistically significantly when correlated to the patient requiring arousal-relieved airway obstruction by verbal or tactile stimulation $(\mathrm{p}=.023)$. For the predictor variable of every point of increase 
in Body Mass Index (BMI), there was a statistically significant correlation with an increase in heart rate during the procedure by $10 \%,(\mathrm{p}=.046)$, a drop in oxygen saturation as measured by pulse oximetry $\left(\mathrm{SpO}_{2}\right)(\mathrm{p}=.002)$, and periods of apnea (respiratory rate less than or equal to 8$)(p=.003)$. Additionally, for every point of increase in BMI there was 1.212 times the odds of requiring verbal or tactile stimulation to relieve airway obstruction $(\mathrm{p}=.002)$. The predictor variable of an STOP-Bang score between 3 and 4, indicating intermediate risk for OSA, was correlated to the development of abnormal $\mathrm{CO}_{2}$ values during the procedure $(\mathrm{p}=$ $0.15)$.

Conclusion: With these findings, proactive safety measures can be instituted for additional airway management for identified at-risk patients. This information has application in the clinical consideration of monitoring protocols, medication administration, equipment availability, and staffing for patients with a high probability for airway obstruction during conscious sedation.

Keywords: Obstructive Sleep Apnea, OSA, STOP-Bang, conscious sedation

Rosemary Bray

May 2019 



\title{
IDENTIFYING PREDICTORS OF AIRWAY COMPLICATIONS IN CONSCIOUS SEDATION PROCEDURES
}

\author{
by \\ Rosemary Bray
}

\author{
A project \\ submitted in partial \\ fulfillment of the requirements for the degree of \\ Doctor of Nursing Practice \\ California State University, Northern Consortium \\ Doctor of Nursing Practice
}

May 2019 


\section{APPROVED \\ For the California State University, Northern Consortium Doctor of Nursing Practice:}

We, the undersigned, certify that the project of the following student meets the required standards of scholarship, format, and style of the university and the student's graduate degree program for the awarding of the Doctor of Nursing Practice degree.

$\frac{\text { Rosemary Bray }}{\text { Project Author }}$

Gail Burmester PhD (Chair)

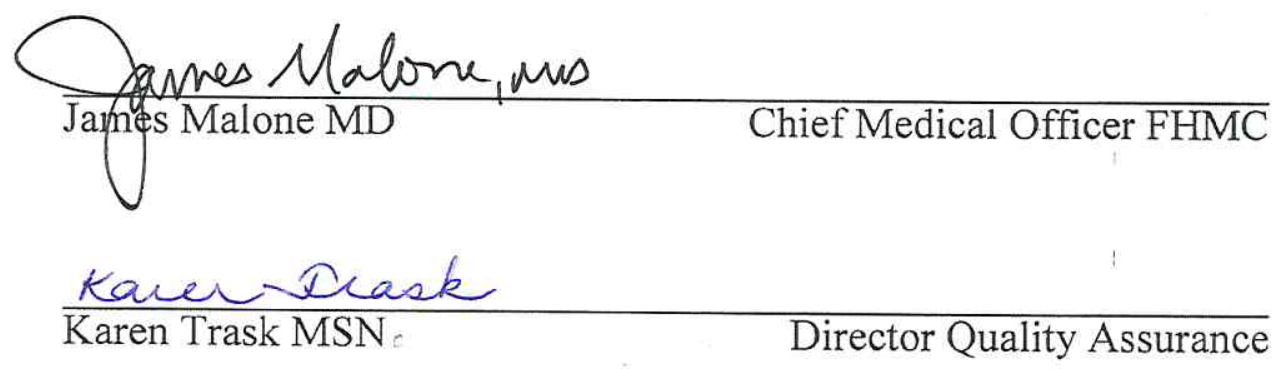




\section{AUTHORIZATION FOR REPRODUCTION}

\section{OF DOCTORAL PROJECT}

$\mathrm{X} \quad \mathrm{I}$ grant permission for the reproduction of this project in part or in its entirety without further authorization from me, on the condition that the person or agency requesting reproduction absorbs the cost and provides proper acknowledgment of authorship.

Permission to reproduce this project in part or in its entirety must be obtained from me.

Signature of project author:

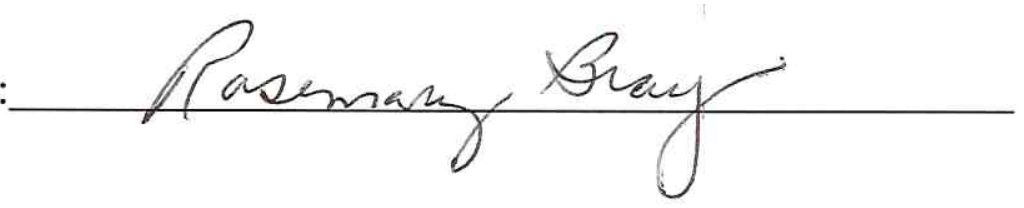




\section{ACKNOWLEDGMENTS}

I would like to thank Dr. Herschel Knapp for his mentorship and guidance throughout this process. His support has been instrumental for me to understand and navigate the research process and the statistical analysis of my data. I would like to thank my committee chair, Dr. Gail Burmeister, and my committee, Dr. James Malone and Karen Trask, for their timely, constructive feedback and guidance. This work would not have been accomplished without the support of my family, especially my husband Mark Bray, children Matthew and Victoria Bray and my mother, Mildred Albanese, for their encouragement and patience. 


\section{TABLE OF CONTENTS}

Page

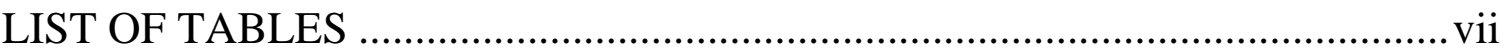

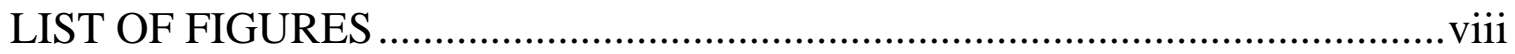

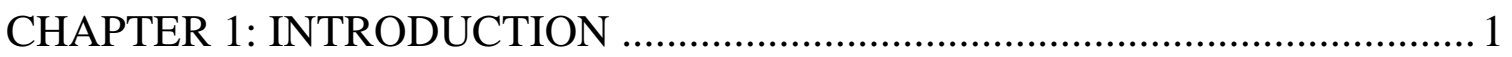

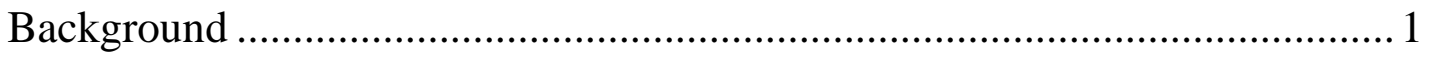

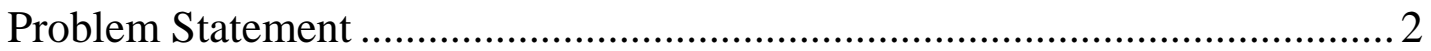

Research Question............................................................................................ 3

Theoretical Framework ……..................................................................... 3

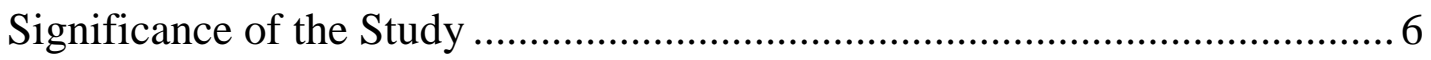

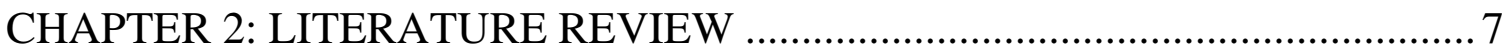

Epidemiology of obstructive sleep apnea (OSA)........................................... 7

Preoperative Patient Evaluation and Evidence-Based Practice Guidelines...... 8

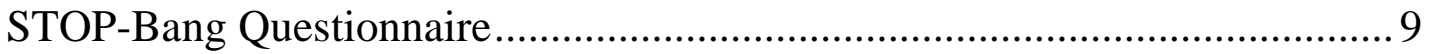

Conscious Sedation Monitoring ....................................................................... 10

Medications used in Conscious Sedation......................................................... 11

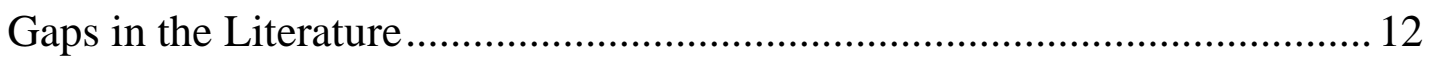

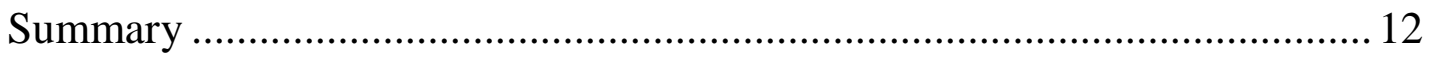

CHAPTER 3: METHODS AND MATERIALS ….............................................. 13

Study Design .................................................................................................... 13

Sample Characteristics ................................................................................. 15

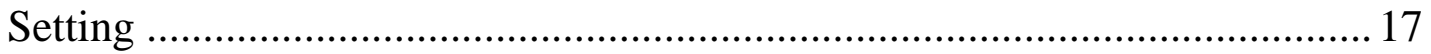

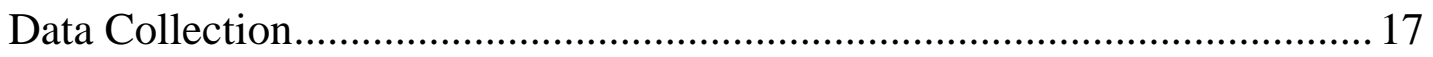

Data Analysis ........................................................................................... 18

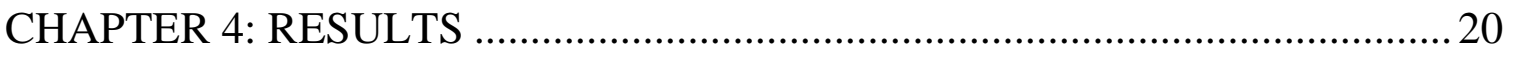




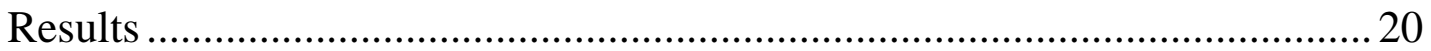

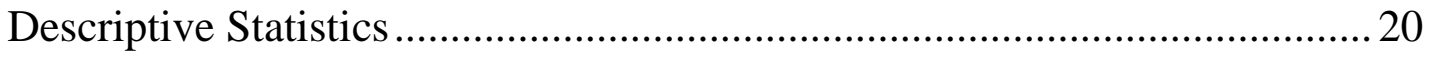

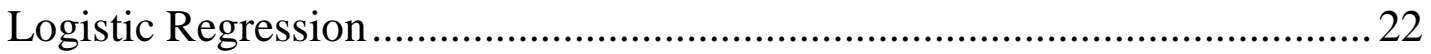

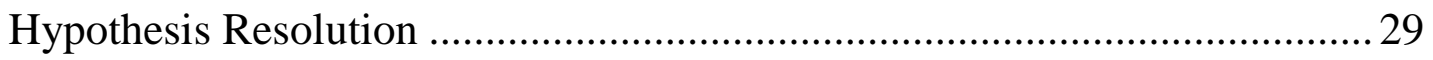

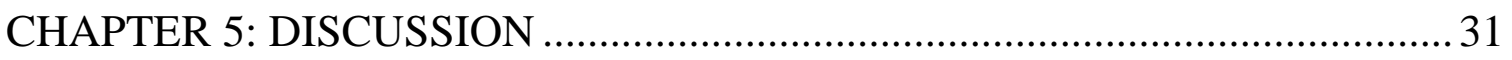

Implications for Nursing Practice .................................................................. 32

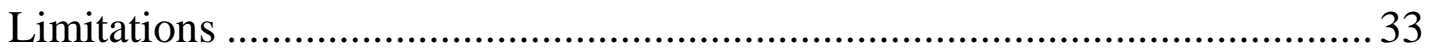

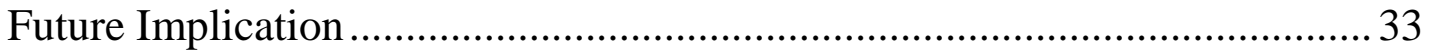

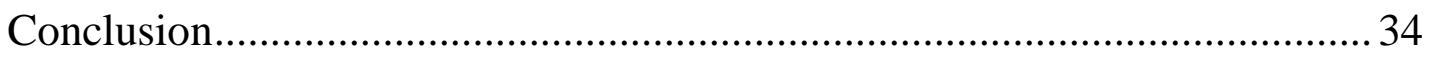

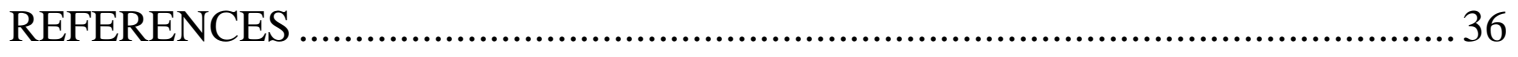

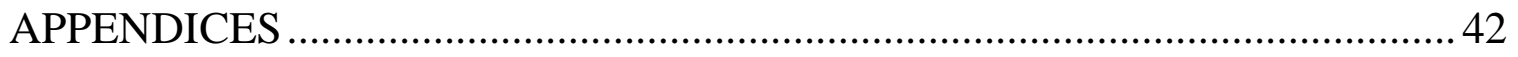

APPENDIX A: PARTICIPANT AND ORGANIZATIONAL

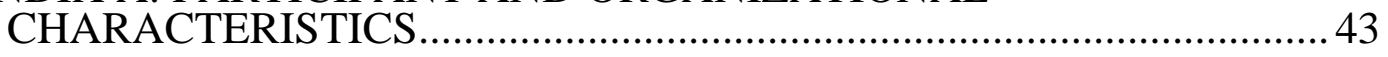

APPENDIX B: PATIENT DATA COLLECTION TOOL ....................................... 47

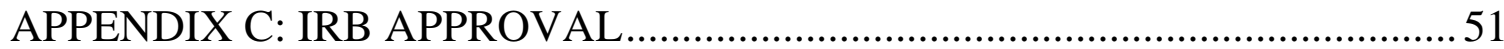




\section{LIST OF TABLES}

Page

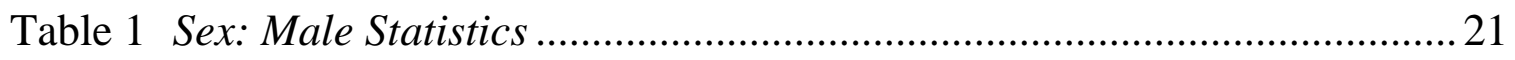

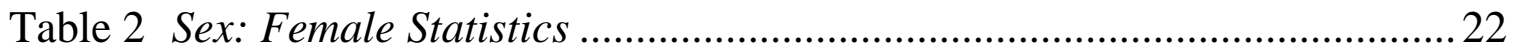

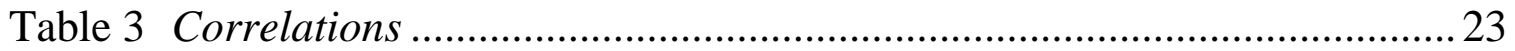

Table 4 Variables in the Equation: Change in heart rate of greater than 10\% from baseline ............................................................................................ 25

Table 5 Variables in the Equation: Abnormal End-Tidal $\mathrm{CO}_{2}\left(\mathrm{ETCO}_{2}\right)$ values greater than 45 or less than 35 .............................................................. 26

Table 6 Variables in the Equation ..................................................................... 27

Table 7 Variables in the Equation Periods of Apnea greater than 8 seconds...... 28

Table 8 Variables in the Equation - Arousal-relieved airway obstruction............ 29 


\section{LIST OF FIGURES}

Page

Figure 1. The IOWA Model revised: Evidence-based practice to promote excellence in health care. Used/reprinted with permission from the University of Iowa Hospitals and Clinics, copyright 2015. For permission to use or reproduce, please contact the University of Iowa Hospitals and Clinics at 319-384-9098. ........................................... 5 


\section{CHAPTER 1: INTRODUCTION}

The purpose of this data research study was to conduct a retrospective medical record review of patients undergoing conscious sedation procedures to identify predictors of risk associated with procedural conscious sedation. The goal was acquiring data to formulate practice improvements in conscious sedation airway management. All patients undergoing sedation received a pre-admission obstructive sleep apnea (OSA) screening tool. The study sought to find out if these same screening criteria, as independent variables, could predict physiologic signs of airway obstruction and procedural airway management, as dependent outcome variables, through logistic regression analysis and measuring the relationship between variables. Medications given in the procedure were treated as continuous independent variables in dose amounts and as a categorical independent variable in medication combinations (fentanyl plus midazolam and Demerol plus midazolam) and included in the analysis. The OSA screening tool used was the STOP-Bang questionnaire which is an acronym for "snoring, tiredness, observed apnea, blood pressure, body mass index (BMI), age, neck circumference, and gender" (University of Toronto, 2012).

\section{Background}

As a validated OSA screening tool, the STOP-Bang questionnaire (2012) has been reported to have a sensitivity for identifying patients with moderate OSA. Each of the eight questions scores a 1 for a "yes" answer, allowing for a total STOP-Bang score ranging from zero to eight. A STOP-Bang score of greater than 3 is considered "at risk" or "intermediate risk" for OSA and a score of 5 or greater is considered "high risk" (Abdullah \& Chung, 2014, pg. 21). The STOP-Bang screening questionnaire (2012) has been correlated to polysomnogram (PSG) 
testing for sleep apnea in predicting moderate-to-severe sleep apnea, with a sensitivity and specificity of $90.6 \%$ and $90 \%$ respectively (Nishadh, Ameer \& Arjun, 2017, pg. e144).

The STOP-Bang was developed because there was a need to reliably screen patients for OSA in the absence of a polysomnography-confirmed OSA diagnosis (Chung, Abdullah, \& Lio, 2016). The most common type of sleep-disordered breathing is OSA and a substantial portion of the population remain undiagnosed. The low-cost, ease, and reliability of screening questionnaires for OSA increase clinician's ability to assess for OSA in the absence of polysomnography confirmation of the diagnosis (Mahmoud, Sallma, \& Mohammad, 2014). Obstructive sleep apnea is a predicting factor of airway management challenges, commonly referred to as a "difficult airway" in obese patients, yet obesity as a single factor does not predict a difficult airway (Toshniwal, Mckelvey, \& Wang, 2014, pg. 361). The American Society of Anesthesiologists physical status (ASAPS) classification system grades overall pre-operative physical status and does not directly address OSA, leaving anesthesiologists reliant on another assessment method to evaluate this risk (Sankar, Johnson, Beattie, Tait, \& Wijeysundera, 2014).

\section{Problem Statement}

Patients may experience unanticipated airway compromise and airway obstruction during elective conscious sedation procedures. This may be due to diagnosed or undiagnosed OSA exacerbated by the impact of benzodiazepines and opioids or from deeper-than-intended states of sedation. The STOP-Bang questionnaire (University of Toronto, 2012) screens for undiagnosed OSA with eight questions. Four of these questions are considered subjective in that they 
cannot be verified by the health care provider. These include snoring at loudly at night, feeling tired during the day, having apnea observed during sleep and being treated for high blood pressure (University of Toronto, 2012). The verifiable,

objective questions are BMI more than $35 \mathrm{~kg} / \mathrm{m}^{2}$, age over fifty years, neck size (males greater than 17 inches and females greater than 16 inches), and gender (University of Toronto, 2012). Admission practices such as relying on stated or estimated weight, height, and neck circumference instill a potential source of error into the questionnaire results. Patients may not be fully aware of, or willing to admit to, sleep-disordered breathing. These factors contribute to a potential lack of reliability of the scoring results in accurately reflecting the risk of OSA.

\section{Research Question}

The research question was to find out if variables within the STOP-Bang questionnaire could act as a predictor of airway complications during conscious sedation procedures. The question was posed; to what extent does the STOP-Bang score variables reliably predict airway complications in conscious sedation procedures? This information has value in the clinical consideration of medication administration, equipment availability and staffing, such as additional respiratory therapy support or monitored anesthesia care, in patients with a high probability for airway obstruction based on their STOP-Bang score. The study was a review of the care given and there was no intention to provide extra treatment or change or alter the normal course of the procedure or care given.

\section{Theoretical Framework}

The Iowa Model Revised: Evidence-Based Practice to Promote Excellence in Health Care was used as a theoretical framework for this data research study (White \& Spruce, 2015, pg. 52). The IOWA model (see Figure 1) is a process 
model that provides the theoretical framework for translating research into practice (Nilsen, 2015, pg. 3). This data research study fits into the first phase of the model which is identifying a knowledge-focused trigger through data collection and new research (White \& Spruce, 2015, pg. 53).

According to Fawcett (2018) predictive theories lend themselves to experimental research design and translates into practice through intervention protocols (Fawcett, 2018, pg. 655). This study analyzed data through descriptive statistics and statistical analysis that measures relationships between variables, specifically logistic regression for continuous and dichotomous variables. The analysis identified predictors of potential airway compromise and obstruction in conscious sedation as determined by specific criteria within the STOP-Bang OSA screening tool.

Findings from the study serve as evidence for quality improvement including the development of assessment tools and protocols. The data provides the basis for development of perioperative documentation standards and assessment tools, strategizing physical and human resources, and promoting multidisciplinary professional communication, all with the intention to improve patient safety during conscious sedation through the translation of research into clinical practice change (Fawcett, 2015, pg. 657). Developing a clinical culture of inquiry allows change to nourish a dynamic evidence-based practice environment and embrace emerging new research (Fawcett, 2015). 


\section{The lowa Model Revised: Evidence-Based Practice to Promote Excellence in Health Care}

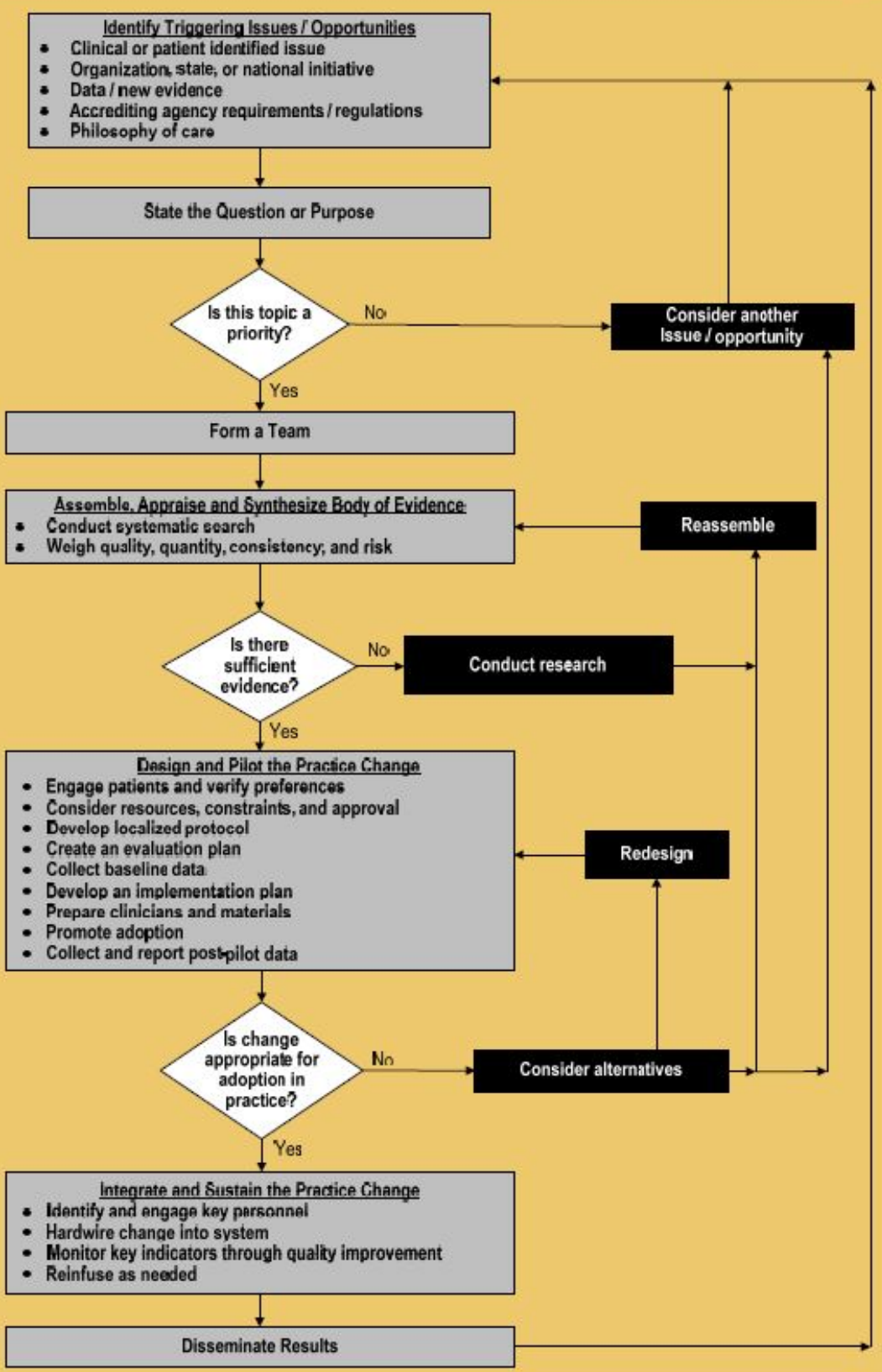

Figure 1. The IOWA Model revised: Evidence-based practice to promote excellence in health care. Used/reprinted with permission from the University of Iowa Hospitals and Clinics, copyright 2015. For permission to use or reproduce, please contact the University of Iowa Hospitals and Clinics at 319-384-9098. 


\section{Significance of the Study}

The rationale for the study was to understand the likelihood of a patient experiencing acute airway obstruction while undergoing conscious sedation based on their STOP-Bang score; such findings are significant in the safe administration of conscious sedation. Other predictors pertaining to the patient's health characteristics were also of interest in this study. An outcome quality measures for patients with OSA is to improve "detection and categorization of OSA" (Aurora et al., 2015, pg. 359). The protocol of screening all preoperative and pre-procedure patients for OSA provides the immediate need of assessing airway obstruction risk of patients prior to conscious sedation. This is a quality process that supports the outcome to improve disease detection (Aurora et al., 2015).

As a data research study, the goal of the study is to see if STOP-Bang scores may act as a predictor for airway obstruction. For the purposes of this study and discussion, airway obstruction is the trajectory of symptoms from impending or actual airway compromise to maneuvers intended to relieve the obstruction. Information obtained from the medical record review gave valuable insight to improve quality processes within the hospital, specifically around patient safety to improve care during conscious sedation procedures and develop future quality improvement recommendations. 


\section{CHAPTER 2: LITERATURE REVIEW}

The literature review explored the epidemiology of OSA in the general adult population, preoperative patient evaluation including the advantages of presedation OSA screening, the STOP-Bang OSA screening questionnaire, conscious sedation monitoring, and medications used in conscious sedation. The literature review helped to guide the research study design. The search for relevant literature was conducted through multiple databases and electronic resources available at Fresno State Henry Madden Library and included Pub Med, Cochrane Library Cochrane Database of Systematic Reviews (EBSCO), SAGE Journals online, Springer Link, and Science Direct (Elsevier).

\section{Epidemiology of Obstructive Sleep Apnea}

Obstructive sleep apnea is one of the most prevalent sleep disorders within the general category of conditions referred to as sleep-disordered breathing, severely effecting $3-7 \%$ of males and $2-5 \%$ of females in the population (Aurora et al., 2015). Studies of OSA confirmed with polysomnography criteria increase these estimates to $24 \%$ in males and $9 \%$ in females. The syndrome is not commonly treated as an estimated $75-80 \%$ of cases are undiagnosed (Aurora et al. 2015). Young, Peppard and Gottlieb (2002) estimated in their epidemiology study that between 17 and 24 percent of North American adults are impacted by OSA. The prevalence of OSA in the adult U.S population is estimated to be $12 \%$ according to Frost and Sullivan white paper on the OSA (American Academy of Sleep Medicine, 2016).

In people with obstructive sleep apnea, the cause of obstruction is the repetitive partial or complete obstruction of their upper airway that results in apnea or hypopnea and resulting hypoxemia (Choi, Hur, Lee, \& Clark, 2010). During 
these periods of non-breathing (apnea) or shallow breathing (hypopnea) oxygen saturation drops causing hypoxemia and hypercapnia (Carvalho, Hsia, \& Capasso, 2012). Normal sleep cycles are broken and the sympathetic nervous system is activated. Repeated nightly assaults cause people to become forgetful, moody, and chronically exhausted. While untreated OSA patients are fighting to stay awake, they grow more obese, hypertensive, and develop risks for other cardiovascular and metabolic diseases (Weaver \& Sawyer, 2010).

The increasing prevalence of obesity in the general population give cause for concern that OSA is on the rise as well (Peppard \& Hagen, 2017). While related to obesity, there are genetic attributions to OSA, including structure of the face, jaw and airway, which account for approximately 33\% of the syndrome (Peppard \& Hagen, 2017). According to Adullah et al., (2014) evidence is mounting the OSA may be an "independent risk factor for perioperative complications” (Abdullah et al., 2014, pg. 20).

\section{Preoperative Patient Evaluation and Evidence- Based Practice Guidelines}

The advantages of preoperative screening apply to pre-procedural patient evaluation to mitigate risk and optimize patient safety. Polysomnography claims to be the gold standard for the confirming the diagnosis of sleep apnea and is able to differentiate between central sleep apnea and OSA (Abdullah et al., 2014). Screening for OSA for patients who are going to undergo any form of anesthesia allows the health care team to anticipate potential problems based on the patient's individual characteristics and provide enhanced procedural safety. Administration of sedation and analgesia to a minimal level that allows for a pain-free experience and provides amnesia of the event, permits the technical aspects of the endoscopic procedure to be completed (Early et al., 2018). The American Society for 
Gastrointestinal Endoscopy (ASGE) established guidelines for sedation and anesthesia during endoscopic procedures (Early et al., 2018). From their metaanalysis of the evidence, standards of competency training for conscious sedation of any provider is to include understanding the continuum of sedation from minimal to moderate or "conscious" sedation, and include the skills to recognize and intervene in deeper-than-intended states of sedation (Early et al., 2018).

\section{STOP-Bang Questionnaire}

The STOP-Bang questionnaire has been studied as a screening tool to predict OSA. Chung et al. (2012) used logistic regression analysis in predicating the probability of STOP-Bang scores predicting OSA in a surgical population by correlating the STOP-Bang scores to apnea-hypopnea index (AHI) scores that were obtained from polysomnography. All OSA was defined as an AHI of greater than 5 apnea or hypopnea events per hour, moderate to severe OSA was defined as having an AHI of greater than 15 events per hour, and severe was defined as having an AHI of greater than 30 events per hour. The predictive probability of having OSA trended to a positive probability as the STOP-Bang score increased (Chung et al., 2012).

A study examining the accuracy of the STOP-Bang questionnaire in relationship to PSG resulted in a sensitivity and specificity of the STOP-Bang score at $90.6 \%$ and $90 \%$ respectively (Nishadh, Ameer \& Arjun, 2017). The use of OSA screening instruments designed for clinical settings separates patients into high and low pre-test probability for moderate to severe OSA (Douglas et al., 2017).

The validity of the STOP-Bang screening tool is seen as a valuable and inexpensive way to triage for OSA in the health care. Patients who screen positive 
on the STOP-Bang questionnaire currently have an advantage in obtaining insurance authorization for their procedure in that the tool is a validated screening tool for identifying OSA patients in surgical populations (Doshi et al., 2015). The STOP-Bang questionnaire has been found to be beneficial in obtaining authorization for sleep studies for patients in the community who were referred to a sleep center for formal testing. While any elective sleep study requires preauthorization, as a validated screening tool, the STOP-Bang is an inexpensive simple tool to administer and will help validate the health care provider's request (Doshi et al., 2015).

\section{Conscious Sedation Monitoring}

The American Society of Anesthesiologist recommends that patients be monitored continuously for oxygenation with pulse oximetry and for ventilation with end-tidal carbon dioxide $\left(\mathrm{ETCO}_{2}\right)$ monitoring, commonly performed through non-invasive capnography monitoring, during conscious sedation (Gross et al., 2002). In a study by Fanari et al., (2018) noted that hypoxia, as indicated by a drop in $\mathrm{SpO}_{2}$, was seen in $22 \%$ of the 18 patients investigated for the effects of sedation on arterial blood gases. These authors felt that supplemental oxygen increased the risk for hypoventilation due to the "false assurance" (pg. 6) of a $\mathrm{SpO}_{2}$ value within a normal range.

Adams, Butas and Spurlock (2015) studied 200 adult patient undergoing conscious sedation for a transesophageal echocardiography (TEE) procedure. The authors investigated the impact of opioids and benzodiazepines on respiratory depression and found that patients receiving hydromorphone had a lower baseline respiratory rate as compared to other opioids $(\mathrm{t}=-2.003, \mathrm{p}=<.05)$. Capnography $\left(\mathrm{ETCO}_{2}\right)$ monitoring was the first alert of respiratory depression in patients, while 
a reduction in oxygen saturation by pulse oximetry $\left(\mathrm{SpO}_{2}\right)$ was a late finding and only seen in 5 (5.5\%) of the 90 patients who demonstrated respiratory depression in the procedure (Adams et al., 2015).

\section{Medications used in Conscious Sedation}

Conscious sedation procedures commonly rely on benzodiazepines and opioids for sedation. Midazolam is a short-acting benzodiazepine sedative commonly given as part of conscious sedation. Opioids in particular have a respiratory depressant effect, decreasing both respiratory rate and tidal volume. Benzodiazepines have a variable decrease in ventilator response to carbon dioxide $\left(\mathrm{CO}_{2}\right)$ levels and spontaneous minute volume contributing to hypopnea while opioids consistently contribute to this phenomenon (Fanari et al., 2018, pg. 1). Opioids can also decrease the bodies "chemo-responsiveness to hypercapnia or hypoxia and decrease upper airway muscle tone” (Junna, Selin, \& Morgenthaler, 2013, pg. 43). Obstructive sleep apnea is correlated with cardiovascular disease comorbidities: cardiovascular diseases such as acute myocardial infarction, heart failure, arrhythmias, and hypertension (American Academy of Sleep Medicine, 2016).

The STOP-Bang questionnaire is associated with a high degree of accuracy as described in a meta-analysis of the literature which reported that the higher the STOP-Bang score, the higher the probability of moderate to severe OSA (Nagappa et al., 2015). According to the meta-analysis results of Nagappa et al. (2015), a stepwise increase of the STOP-Bang score from 4 to 8 showed the corresponding probability of OSA increasing from $25 \%$, to $65 \%$, respectively. 


\section{Gaps in the Literature}

The gaps in the literature review was the absence of OSA screening tools that predict airway complications. The tools provide assessment of risk of OSA however do not extrapolate how that risk translates to predicting potential complications based on identified risks. The research design was intended to fill this gap. The investigators intention was to provide research that translates to improve clinical practice in monitoring conscious sedation patients.

\section{Summary}

The literature review supported the research question and the choice of predictor independent variables and outcome dependent variables. The literature review also informed the design of the patient data collection tool. A research study design that looked at the individual question within the STOP-Bang questionnaire as independent predictors of airway obstruction was not found. Related research studies on STOP-Bang questionnaire as a screening tool for OSA and the impact of opioids and benzodiazepine medications on the airway provided direction for the study design and method of this data research study. 


\section{CHAPTER 3: METHODS AND MATERIALS}

The method of this data research study was to collect data from the electronic medical record (EMR) of patients who have undergone conscious sedation for endoscopy services, specifically for the variables of the STOP-Bang score, physiologic data and any documented airway maneuvers required open the patient's airway during the procedure. Conscious sedation medication dose data was collected to account for sedation effect as part of the data analysis. The benefit of the study findings is the application of the results to quality processes within the hospital, such as evaluation of existing assessment tools, post procedure recovery protocols and strategies for anesthesia selection and procedural airway management.

Dignity Health and California State University Fresno School of Nursing Internal Review Board (IRB) determined this study to be minimal risk as a retrospective medical records review. The study did not require informed consent but did require protection of patient information by de-identification of data and maintenance of temporary study paper documents according to Health Insurance Portability and Accountability Act of 1996 (HIPAA) standards.

\section{Study Design}

This data research study design was a manual, retrospective medical records review of adult patients (age 18 years and older) who had conscious sedation for endoscopic procedures. The following independent variables were examined (a) demographics for age, sex, height, and weight; (b) pre-procedure STOP-Bang questionnaire scores; (c) medication used for sedation, as predictors of airway compromise or obstruction. The dichotomous predictor variables included the "yes", "no" answers to the STOP-Bang questionnaire. The continuous 
predictor variables were the height, weight, age, total scores of the STOP-Bang questionnaire, and total doses of medications used to achieve conscious sedation.

The outcome variables were physiologic signs of airway obstruction as well as airway interventions used to relieve any obstruction observed during the conscious sedation procedure. Airway obstruction is ordered on the trajectory from physiologic signs of airway compromise to actual obstruction, as indicated by physical maneuvers to relieve airway obstruction.

The above predictor variables were correlated to the following outcome variables (see Appendix A):

1. Physiologic data outcomes of airway obstruction during conscious sedation included any of the following:

a. Audible snoring or stridor;

b. Change in heart rate greater than $10 \%$ from baseline;

c. Development of arrhythmia;

d. Abnormal End Tidal $\mathrm{CO}_{2}$ value $<35$ mmHg or $>45$ mmHg;

e. Drop in $\mathrm{SpO}_{2}$ value more than 3\% from baseline;

f. Periods of apnea greater than 8 seconds.

2. Outcome variables of basic or advanced airway maneuvers which included any development of airway compromise or obstruction during conscious sedation that required interventions:

a. Basic Airway Maneuvers

i. Jaw thrust;

ii. Head-tilt, Chin-lift;

iii. Arousal-relieved airway obstruction or the ability of patient to respond to verbal command, such as "take a deep breath”, tactile or other stimulation. 
b. Advanced airway maneuvers

i. Suctioning;

ii. Oral or nasal airway placement;

iii. Bag-valve ventilation;

iv. Continuous positive airway pressure (CPAP) or bilevel positive airway pressure (Bi-pap) for respiratory support;

v. Advanced airway placement (Such as endotracheal tube or laryngeal mask airway).

The research study design was collecting retrospective data from the EMR. All paper documentation that was accessed for information was electronically scanned into the medical record, therefore the EMR was the source of all data collection. During the retrospective medical record review, data collected was entered into a de-identified, chronologically numbered, patient collection tool (see Appendix B). In designing the study, logistic regression was chosen for the statistical analysis of the data. This statistic can identify the odds of a predictor variable determining the likelihood of a binary or dichotomous outcome (Knapp, 2017).

\section{Sample Characteristics}

The source of the study data was a manual retrospective medical record review of patients that underwent conscious sedation during an endoscopic procedure from January 15, 2019 through April 22, 2019. Two hundred and three charts were identified through a search of CERNER@ EMR patient list of endoscopic procedures. After review and consideration of inclusion and exclusion criteria, the final sample size was 152 medical records. No participants were 
recruited for this study, as this was a retrospective study using existing data from a medical record review of patient receiving conscious sedation while undergoing an endoscopic procedure.

\section{Inclusion and Exclusion Criteria}

Inclusion criteria for conscious sedation procedures were bronchoscopy, colonoscopy, esophagogastroduodenoscopy (EGD), esophagoscopy, flexible sigmoidoscopy, and TEE. Inclusion criteria also included patient who received moderate conscious sedation administered by a registered nurse who has demonstrated competency in medication administration of sedation and analgesia. Competency requirements included the ability to rescue patients from a level of sedation that was deeper than intended, including management of a compromised airway, and the provision of oxygenation and ventilation.

Exclusion criteria for this retrospective medical record review were patients who had conscious sedation administered by a physician, did not have a STOPBang screening performed, did not receive sedation or analgesia, were hemodynamically unstable, or had a pre-existing advanced artificial airway such as endotracheal intubation or tracheostomy. Patients that had two or more missing data elements were also excluded from the study.

\section{Body Mass Index (BMI)}

The calculations for body mass index is calculated automatically in the CERNER $@$ EMR based on a measured height and scale weight of each patient. Guidelines used for determination of BMI range were those described by the World Health Organization (WHO) and U.S. centers for Disease Control and Prevention (CDC). Underweight is a BMI of less than $18.5 \mathrm{~kg} / \mathrm{m}^{2}$, normal BMI range is 18.5 to $24.9 \mathrm{~kg} / \mathrm{m}^{2}$, overweight is a BMI of 25 to $29.9 \mathrm{~kg} / \mathrm{m} 2$, obesity 
(class 1 ) is 30 to $34.9 \mathrm{~kg} / \mathrm{m} 2$, severe obesity (class 2) $35-39.9 \mathrm{~kg} / \mathrm{m} 2$, and extreme or morbidly obese (class 3) is a BMI of 40 or higher (Centers for Disease Control and Prevention, 2017; National Institute of Health, National Heart, Lung, Blood Institute, 2010).

\section{Setting}

The setting was a retrospective medical review of patients who had undergone conscious sedation administered by a registered nurse for an endoscopic procedure in a single-center, acute care community hospital.

\section{Data Collection}

The source of data collection for this data research study was the patient EMR. A sample size of 152 patient medical records were reviewed. The predictor variables were continuous, or categorical with dichotomous, binary response variables. N-Quota sample size for this logistic regression was 150, so pre-test criteria for n-quota was met with the final sample size of 152 patient medical records. Logistic regression pre-test criteria of histogram for normal curve of the continuous variables, and multicollinearity was performed. Logistic regression was used to determine the relationship between the predictor variables and the physiologic outcome variables of airway obstruction, and to identify which airway maneuvers were used to relieve obstruction. The outcome variables were categorized into physiologic dependent outcome variables, basic airway maneuvers, and advanced airway maneuver. The chart review variables collected were: (a) STOP-Bang score; (b) procedural airway management; (c) sedation medications used to achieve conscious sedation; (d) patient demographic information (age, gender). 
Data collected consisted of scanned paper documentation and digital data entered into the CERNER $@$ Corporation EMR platform. Selected portions of the EMR were accessed for collecting and documenting data following standard HIPAA guidelines. De-identified data was used for statistical analysis in identifying predictors of airway complications in completed conscious sedation procedures. The information was retained for the period of time necessary to analyze the data through reporting and publication, after which the data was destroyed.

The paper data collection tool (see Appendix B) was stored in a locked file with the principle investigator responsible for oversight of the data. All collected data was de-identified upon collection and stored in a password-protected data folder on the Dignity Health file server. Paper data was destroyed by shredding through an onsite Dignity Health shredder. Electronic data was deleted from a Dignity Health file server.

\section{Data Analysis}

The aim of this data research study was a retrospective chart review of patients undergoing conscious sedation procedures correlating the patient's preadmission STOP-Bang score as independent predictor variables with physiologic signs of airway obstruction and airway management as dependent outcome variables. For defining the dependent outcome variables, airway obstruction was defined by the physiological signs of airway compromise and obstruction, and by basic and advanced airway maneuvers that were performed with the intention to relieve obstruction. Logistic regression and descriptive statistics were processed through IBM SPSS Statistics for Windows, Version 24.0. 
The predictor variables of age, sex, observed snoring, history of chronic tiredness during the day, history of high blood pressure, height, weight, BMI, neck circumference, total STOP-Bang score, ranking of STOP-Bang score into low, intermediate, or high risk for OSA, and medications administered for sedation were correlated to the dependent outcome variables. The dependent outcome variables consisted of physiologic outcomes that occurred during the procedure and the immediate phase 1 recovery. These consisted of audible snoring or stridor, change in heart rate greater than $10 \%$ from baseline, development of arrhythmia, abnormal end-tidal $\mathrm{CO}_{2}$ values, drop in oxygen saturation as measured by pulse oximetry and periods of apnea defined as respiratory rate of eight or less. The airway maneuver dependent outcome variables were collected in order from basic to advanced airway maneuvers:

1. Basic airway maneuvers consisted of side lying recovery position, jaw thrust, head-tilt chin-lift, and arousal relieved airway obstruction.

2. Advanced airway maneuvers consisted of suction, oral or pharyngeal airway placement, bag-valve ventilation, continuous or bi-level positive airway pressure (CPAP or BIPAP), and placement of an advanced airway such as an endotracheal tube or laryngeal mask airway.

IBM SPSS Version 24.0 was used to obtain descriptive statistics summarizing patient's demographic data, and STOP-Bang questionnaire data, as mean and standard deviation for the continuous variables, and percentages for the categorical variables. A logical regression analysis was performed using the OSA predictor variables as identified in the STOP-Bang questionnaire. A goodness-of fit was determined to evaluate the fit of a logistic regression. (Knapp, 2017). 


\section{CHAPTER 4: RESULTS}

\section{Results}

A total of 203 patient medical records were reviewed for a final sample size of 152 eligible patients who underwent conscious sedation administered by a registered nurse during an endoscopic procedure.

\section{Descriptive Statistics}

The data set comprised 78 males (51.3\%) and 74 females (48.7\%) that underwent an endoscopic procedure utilizing conscious sedation delivered by a registered nurse who had successfully completed a Dignity Health central coast service area conscious sedation certification program. The male sample population specified a mean age of 69.96 years, a mean height of $176.60 \mathrm{~cm}$, a mean weight of 191.99 pounds (87.26 kg), and a mean BMI of 27.91 which placed the mean BMI for males in the sample population in the category of overweight (National Institutes of Health, National Heart Lung and Blood Institute, n.d.). The mean STOP-Bang score was 3.4 which places the male sample population in the intermediate risk category for OSA (University of Toronto, 2012).

The female sample population specified a mean age of 69.46 years, a mean height of $161.38 \mathrm{~cm}$, a mean weight of 158.26 pounds $(71.94 \mathrm{~kg})$, and a mean BMI of 27.456 which placed the mean BMI for females in the sample population in the category of overweight (National Institutes of Health, National Heart Lung and Blood Institute, n.d.). The mean STOP-Bang score was 2.34 which places the female sample population in the low risk category for OSA (University of Toronto, 2012). Tables 1 and 2 show the mean, median, mode and the standard deviations for the sex variables, male, and female respectively. 
Table 1

Sex: Male Statistics

\begin{tabular}{llllll}
\hline Statistics & Age & Height & Weight & BMI-Calc & TSBS \\
\hline N Valid & 78 & 78 & 78 & 78 & 78 \\
N Missing & 0 & 0 & 0 & 0 & 0 \\
Mean & 69.96 & 176.60 & 191.99 & 27.91 & 3.40 \\
Median & 72.00 & 177.40 & 188.280 & 27.365 & 3.00 \\
Mode & 75 & 180.000 & 185.00 & $29.350 \mathrm{a}$ & 3 \\
Std. & 11.312 & 6.932 & 33.396 & 4.4838 & 1.417 \\
Deviation & & & & & \\
Variance & 127.190 & 48.050 & 1115.291 & 20.104 & 2.009 \\
Range & 56 & 26.00 & 155.00 & 22.440 & 6 \\
Minimum & 37 & 162.00 & 120.00 & 20.240 & 1 \\
Maximum & 93 & 188.00 & 275.00 & 42.680 & 7 \\
\hline
\end{tabular}

Note. BMI-Calc is the patient's calculated BMI; TSBS is the total STOP-Bang Score 
Table 2

Sex: Female Statistics

\begin{tabular}{llllll}
\hline \multicolumn{1}{c}{ Statistics } & \multicolumn{1}{c}{ Age } & \multicolumn{1}{c}{ Height } & Weight & BMI-Calc & TSBS \\
\hline N Valid & 74 & 74 & 74 & 74 & 74 \\
N Missing & 0 & 0 & 0 & 0 & 0 \\
Mean & 69.46 & 161.38 & 158.263 & 27.46 & 2.34 \\
Median & 71.00 & 161.50 & 150.40 & 26.51 & 2.00 \\
Mode & $72 \mathrm{a}$ & 165.00 & $196.00 \mathrm{a}$ & $17.590 \mathrm{a}$ & 2 \\
Std. & 13.530 & 5.8268491 & 37.82159 & 5.791256 & 1.474 \\
Deviation & & & & & \\
Variance & 183.074 & 33.952 & 1430.472 & 33.539 & 2.172 \\
Range & 65 & 26.2600 & 206.00 & 32.730 & 6 \\
Minimum & 30 & 149.0000 & 95.40 & 17.590 & 0 \\
Maximum & 95 & 175.2600 & 301.40 & 50.320 & 6 \\
\hline
\end{tabular}

Note. a Multiple modes exist. The smallest value is shown. BMI-Calc is the patient's calculated BMI; TSBS is the total STOP-Bang Score

\section{Logistic Regression}

A logistic regression analysis was performed to determine the relationship between independent predictor variables to dependent outcome variables (physiologic and airway intervention dependent outcomes variables). Normality pretest criteria were conducted showing normal distribution on a histogram for normal curve. A pretest check for multicollinearity of the continuous predictor variables was performed. There were six highly-correlated predictor variables noted on the correlations table, which were removed from the model and the logistic regression analysis was re-run as seen in Table 3. 
Table 3

Correlations

\begin{tabular}{lllll}
\hline Statistics & & Age & BMI_C & TSBS \\
\hline Age & Pearson Correlation & 1 & -.018 & $.273^{* *}$ \\
& Sig. (2-tailed) & & .825 & .001 \\
& $\mathrm{~N}$ & 152 & 152 & 152 \\
BMI_C & Pearson Correlation & -.018 & 1 & $.516^{* *}$ \\
& Sig. (2-tailed) & .825 & & .000 \\
& N & 152 & 152 & 152 \\
TSBS & Pearson Correlation & $.273^{* *}$ & $.516^{* *}$ & 1 \\
& Sig. (2-tailed) & .001 & .000 & \\
& $\mathrm{~N}$ & 152 & 152 & 152 \\
\hline
\end{tabular}

Note. ${ }^{* *}$. Correlation is significant at the 0.01 level (2-tailed). TSBS is total STOP-Bang score.

Dependent variable encoding is coded as "no" equal to 0 and "yes" equal to 1 . The predicted probability is "of membership for no" for all categorical dependent variables.

\section{Physiologic Dependent Outcome Variables}

Airway obstruction was defined by the physiological signs of airway compromise obstruction and by basic and advanced airway maneuvers that were performed with the intention to relieve obstruction. End-tidal carbon dioxide $\left(\mathrm{ETCO}_{2}\right)$ values were all validated by documentation of positive quality waveform for Philips ${ }^{\circledR} \mathrm{ETCO}_{2}$ monitor and provider visual validation of waveform for Alaris ${ }^{\circledR} \mathrm{ETCO}_{2}$ module. 
Change in heart rate of greater than $\mathbf{1 0 \%}$ from baseline. Logistic regression revealed that for every additional point of increase in BMI, the odds of a change in heart rate greater than $10 \%$ from baseline during conscious sedation increased by $12.7 \%(\mathrm{p}=.046)$ (95\% C.I. 1.002, 1.267). Patients who did not acknowledged a history of observed sleep apnea during sleep had 17.54 times the odds of having a change in heart rate of greater than $10 \%$ from baseline during their conscious sedation procedure compared to patients who acknowledged a history of observed sleep apnea $(\mathrm{p}=.044)$ (95\% C.I. .004, .926). This was an unexpected finding probably because it was a subjective answer based on selfreport. Patients who score as high risk for OSA (STOP-Bang score range between 5 and 8) have 76.033 times the odds of experiencing a change in heart rate greater than $10 \%$ of baseline during a conscious sedation procedure $(\mathrm{p}=.021)(95 \%$ C.I. 1.915, 3019.3). Other independent predictors were found to be statistically insignificant with respect to a change in heart rate of greater than $10 \%$ from baseline occurring during the procedure. 
Table 4

Variables in the Equation: Change in heart rate of greater than 10\% from baseline

\begin{tabular}{|c|c|c|c|c|c|c|c|c|c|}
\hline & & & & & & & Exp & $\begin{array}{r}95 \% \\
\mathrm{E}\rangle \\
\end{array}$ & $\begin{array}{l}\text { C.I. for } \\
\text { XP(B) }\end{array}$ \\
\hline Statis & tics & B & S.E. & Wald & $\mathrm{df}$ & Sig. & (B) & Lower & Upper \\
\hline Step & Age & .047 & .025 & 3.654 & 1 & .056 & 1.049 & .999 & 1.101 \\
\hline $1^{\mathrm{a}}$ & $\begin{array}{l}\text { Observed apnea } \\
\text { during sleep (1) }\end{array}$ & -2.857 & 1.419 & 4.056 & 1 & .044 & .057 & .004 & .926 \\
\hline & BMI-Calc & .119 & .060 & 3.979 & 1 & .046 & 1.127 & 1.002 & 1.267 \\
\hline & $\begin{array}{l}\text { High Risk OSA } \\
\text { (score 5-8) (1) }\end{array}$ & 4.331 & 1.898 & 5.317 & 1 & .021 & 76.033 & 1.915 & 3019.33 \\
\hline & Constant & -5.007 & 2.029 & 6.090 & 1 & 0.014 & 0.007 & & \\
\hline
\end{tabular}

Note. a. Variable(s) entered on step 1: Age, Snoring: History of, Tired: History chronic, Observed apnea during sleep, Pressure: Hx HTN, BMI-Calc, Neck > 16" female; >17" Males, High Risk OSA (score 5-8), Intermediate risk of OSA (score 3-4), Analgesic-Sedation Combination, Sex, Height.

Abnormal $\mathrm{ETCO}_{2}$ values greater than 45 or less than 35. Patients who scored an intermediate risk of OSA predictor variable (total score of 3-4) had 22.361 times the odds of experiencing an abnormal $\mathrm{ETCO}_{2}$ result during their endoscopic procedure ( $\mathrm{p}=.015$ ) (95\% C.I. 1.818; 275.036). Other independent predictors were found to be statistically insignificant with respect to abnormal $\mathrm{ETCO}_{2}$ values occurring during the procedure. 
Table 5

Variables in the Equation: Abnormal End-Tidal $\mathrm{CO}_{2}\left(\mathrm{ETCO}_{2}\right)$ values greater than 45 or less than 35

95\% C.I. for

$\operatorname{EXP}(B)$

$\begin{array}{lllll}\text { Statistics } & \text { B } & \text { S.E. Wald df Sig. Exp (B)Lower Upper }\end{array}$

$\begin{array}{lllllllll}\text { Step } & \text { Intermediate risk } 3.107 & 1.280 & 5.889 & 1 & .015 & 22.361 & 1.818 & 275.036\end{array}$

$1^{\mathrm{a}}$ of OSA (score 3-

4) (1)

$\begin{array}{llllll}\text { Constant } & 4.170 & 2.649 & 2.479 & 1 & 0.11564 .728\end{array}$

Note. a. Variable(s) entered on step 1: Age, Snoring: History of, Tired: History chronic, Observed apnea during sleep, Pressure: Hx HTN, BMI-Calc, Neck > 16"female; >17"Males, High Risk OSA (score 5-8), Intermediate risk of OSA (score 3-4), Analgesic-Sedation Combination, Sex, Height.

Drop in $\mathrm{SpO}_{2}$ value greater than 3\% from baseline. For every point of increase in a patient's calculated BMI, there were 1.223 times the odds of experiencing a drop in $\mathrm{SpO}_{2}$ values during conscious sedation ( $\left.\mathrm{p}=.002\right)(95 \%$ C.I., 1.077, 1.389). Other independent predictors were found to be statistically insignificant with respect to experiencing a drop in $\mathrm{SpO}_{2}$ values occurring during the procedure. 
Table 6

Variables in the Equation

\begin{tabular}{|c|c|c|c|c|c|c|c|c|c|}
\hline \multirow{2}{*}{\multicolumn{2}{|c|}{ Statistics }} & \multirow[b]{2}{*}{ B } & \multirow[b]{2}{*}{ S.E. } & \multirow[b]{2}{*}{ Wald } & \multirow[b]{2}{*}{$\mathrm{df}$} & \multirow[b]{2}{*}{ Sig. } & \multirow[b]{2}{*}{ Exp (B) } & \multicolumn{2}{|c|}{$\begin{array}{c}\text { 95\% C.I.for } \\
\text { EXP(B) }\end{array}$} \\
\hline & & & & & & & & Lower & Upper \\
\hline Step & BMI-Calc & .201 & .065 & 9.602 & 1 & .002 & 1.223 & 1.077 & 1.389 \\
\hline \multicolumn{10}{|l|}{$1^{\mathrm{a}}$} \\
\hline & Constant & -3.95 & 2.010 & 3.865 & 1 & 0.049 & 0.019 & & \\
\hline
\end{tabular}

Note. a. Variable(s) entered on step 1: Age, Snoring: History of, Tired: History chronic, Observed apnea during sleep, Pressure: Hx HTN, BMI-Calc, Neck > 16"female; >17"Males, High Risk OSA (score 5-8), Intermediate risk of OSA (score 3-4), Analgesic-Sedation Combination, Sex, Height.

Apnea (respiratory rate less than or equal to eight). For every point of increase in a patient's calculated BMI, the odds of experiencing periods of apnea during conscious sedation increased by $38.6 \%(\mathrm{p}=.003)(95 \%$ C.I., 1.116, 1.722). The odds of experiencing apnea (respiratory rate of 8 or less) during a conscious sedation procedure are 2,218.92 times the higher for patients who scored as high risk on the STOP-Bang OSA screening questionnaire as compared to patients who did not score in that range $(\mathrm{p}=0.003)$ (C.I. 12.707, 387458.9). Other predictors were found to be statistically insignificant with respect to apnea occurring during the procedure. 
Table 7

Variables in the Equation Periods of Apnea greater than 8 seconds

95\% C.I.for

EXP(B)

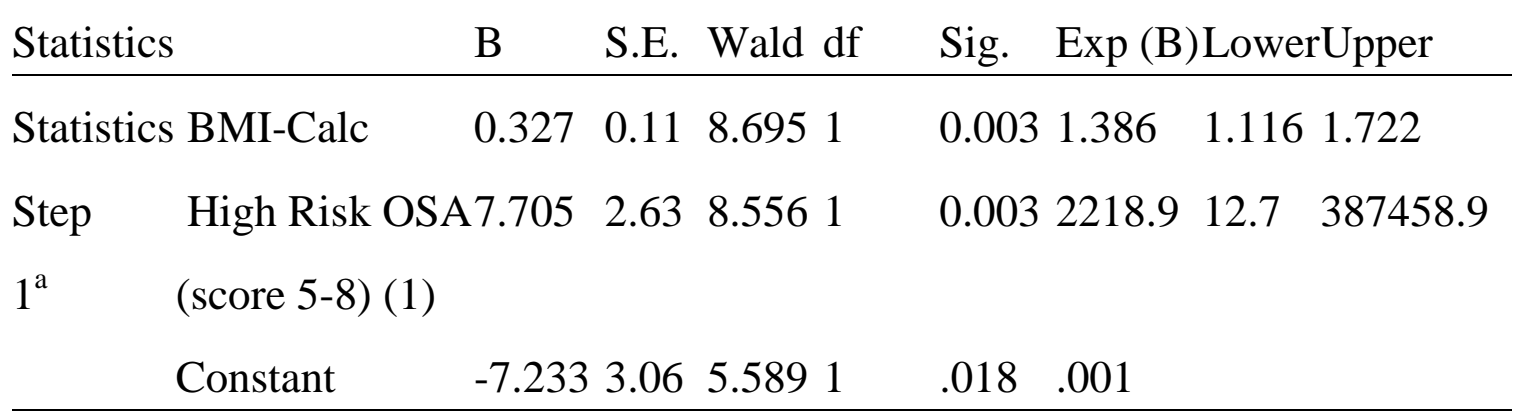

Note. a. Variable(s) entered on step 1: Age, Snoring: History of, Tired: History chronic, Observed apnea during sleep, Pressure: Hx HTN, BMI-Calc, Neck > 16" female; >17" Males, High Risk OSA (score 5-8), Intermediate risk of OSA (score 3-4), Analgesic-Sedation Combination, Sex, Height.

\section{Basic Airway Maneuvers}

For every point of increase in a patient's calculated BMI, there was 1.212 times the odds of requiring arousal during sedation $(\mathrm{p}=.002)(95 \%$ C.I., 1.074, 1.367). The odds of experiencing arousal-relieved airway obstruction by verbal or tactile stimulation during a conscious sedation procedure are 37.320 times the higher for patients who scored as high risk on the STOP-Bang OSA screening questionnaire as compared to patients who did not score in that range $(\mathrm{p}=0.023)$ (C.I. 1.651, 843.613). Other independent variable predictors were found to be statistically insignificant with respect to arousal-relieved airway obstruction occurring during a conscious sedation procedure. 
Table 8

Variables in the Equation - Arousal-relieved airway obstruction

$$
\text { 95\% C.I.for }
$$

\begin{tabular}{|c|c|c|c|c|c|c|c|c|}
\hline \multirow{2}{*}{\multicolumn{2}{|c|}{ Statistic }} & \multirow[b]{2}{*}{$\mathrm{B}$} & \multirow[b]{2}{*}{ S.E. } & \multirow[b]{2}{*}{ Wald } & \multirow[b]{2}{*}{ Df } & \multirow[b]{2}{*}{ Sig. } & \multirow{2}{*}{$\begin{array}{l}\text { Exp } \\
\text { (B) }\end{array}$} & EXP(B) \\
\hline & & & & & & & & Lower Upper \\
\hline Step & BMI-Calc & .192 & .061 & 9.780 & 1 & .002 & 1.041 & 1.0741 .367 \\
\hline \multirow[t]{2}{*}{$1 \mathrm{a}$} & $\begin{array}{l}\text { High Risk OSA } \\
\text { (score 5-8) }\end{array}$ & 3.620 & 1.591 & 5.176 & 1 & 0.023 & 37.32 & 1.651843 .613 \\
\hline & Constant & -6.115 & 2.015 & 9.206 & 1 & 0.002 & 0.002 & \\
\hline
\end{tabular}

Note. a. Variable(s) entered on step 1: Age, Snoring: History of, Tired: History chronic, Observed apnea during sleep, Pressure: Hx HTN, BMI-Calc, Neck > 16"female; >17"Males, High Risk OSA (score 5-8), Intermediate risk of OSA (score 3-4), Analgesic-Sedation Combination, Sex, Height.

\section{Advanced Airway Maneuvers}

There were no independent predictors found to be statistically significant in regard to the advanced airway outcome variables occurring during the procedure (airway suction, oral or nasal pharyngeal placement, bag-valve ventilation, continuous positive pressure or advanced airway placement).

\section{Hypothesis Resolution}

The aim of the study was reflected in the research question and resulting hypothesis: Will the STOP-Bang screening tool for obstructive sleep apnea predict airway obstruction in patients undergoing conscious sedation?

- $\mathrm{H}_{\mathrm{O}}$ : Patients who undergo conscious sedation will have no difference in procedural conscious sedation airway obstruction 
requiring airway intervention as predicted by their pre-procedure STOP-Bang score and other health characteristics.

- $\mathrm{H}_{\mathrm{A}}$ : Patients who undergo conscious sedation will have an increase in procedural conscious sedation airway obstruction requiring airway intervention as predicted by their pre-procedure STOP-Bang score and other health characteristics.

The null hypothesis was rejected. The alternative hypothesis was accepted. 


\section{CHAPTER 5: DISCUSSION}

The expected outcome was to discover which STOP-Bang variables were associated with airway obstruction. The findings of this study confirmed the predictive validity of the STOP-Bang questionnaire. While conscious sedation is overall considered a safe procedure, the findings from this study did identify specific predictor characteristics that would enable heath care providers to better prepare patients for procedural conscious sedation. As a data research study, the intention of the study was to see if STOP-Bang scores could act as a surveillance tool and predictor for airway obstruction. This information provides valuable insight to improve quality processes within the hospital, specifically pertaining to patient safety.

A STOP-Bang threshold score of greater than 5, indicating a high risk for OSA, was determined to be predictive of a heart rate change greater than $10 \%$ from baseline during the procedure $(\mathrm{p}=.021)$ and periods of apnea of (respiratory rate less than or equal to 8 seconds) $(\mathrm{p}=.038)$, indicating airway compromise. The STOP-Bang threshold score of greater than 5 was statistically significantly when correlated to the patient requiring arousal-relieved airway obstruction by verbal or tactile stimulation $(\mathrm{p}=.023)$. For every point of increase in Body Mass Index (BMI), there was a statistically significant correlation with an increase in heart rate during the procedure by $10 \%$, $(\mathrm{p}=.046)$, a drop in oxygen saturation as measured by pulse oximetry $\left(\mathrm{SpO}_{2}\right)(\mathrm{p}=.002)$, and periods of apnea (respiratory rate less than or equal to 8$)(\mathrm{p}=.003)$. This predictor variable was also correlated to the outcome variable of arousal-relieved airway obstruction $(\mathrm{p}=.002)$. The predictor variable of a STOP-Bang score between 3 and 4, indicating intermediate risk for OSA, was correlated to abnormal $\mathrm{CO}_{2}$ values during the procedure $(\mathrm{p}=0.15)$. The 
results revealed areas to anticipate patient care needs during conscious sedation procedures and to develop future quality improvement recommendations, furthering patient safety.

\section{Implications for Nursing Practice}

With the data results obtained, the principle investigator identified areas to improve patient care during conscious sedation procedures and develop future quality improvement recommendations. These areas include

- communication of STOP-Bang screening results and referral to anesthesia if their score if over 5;

- accuracy of measurement of height, weight and neck circumference;

- notification of the patient's primary health care provider after patient discharge from the hospital of a STOP-Bang score indicating intermediate or high risk for OSA;

- incorporating STOP-Bang risk scores as part of the nurse hand-off report;

- employee education to include STOP-Bang score and ETCO $\mathrm{ET}_{2}$ monitoring as baseline entry level education and annual competency;

- patient education and discharge planning to include referral to case management with the results of the STOP-Bang screening tool to promote referral for sleep apnea;

- development of EMR documentation flow sheet and ad hoc forms,

- during procedure with oral endoscope, use oral bite block with $\mathrm{ETCO}_{2}$ sensor; and

- the addition of STOP-Bang OSA screening questionnaire into emergency department and inpatient adult admission form. 


\section{Limitations}

Limitations of this study are that it was a retrospective audit of nurseadministered conscious sedation for endoscopy procedures in a single community hospital setting. Although all efforts were made to control for internal validity in this study, external validity for this one-site pilot study may not be reasonably generalized to other populations. Limitation of this study were identified as follows:

- The STOP-Bang OSA screening questionnaire is an adult screening tool and cannot be used with pediatric patients.

- The study did not account for comorbidities.

- The CERNER@ EMR did not have discrete data cells for all the variables collected.

- Apnea and hypopnea with irregular respirations were not well captured.

- Monitoring $\mathrm{ETCO}_{2}$ was challenging for oral endoscopic procedures as the sensor was often moved away from the mouth, voiding these values.

- Some STOP-Bang question variables were subjective and could not be verified.

- The study did not include other screening tools such as ASA-PS and Mallampati assessment. While these metrics were not included in our medical records, future research may include if the outcome variable correlate or if they correlate with each other.

\section{Future Implication}

Future implications for research and quality improvement would focus on analyzing objective criteria to predict adverse outcomes. As a result of this study, 
the study site plans to send notification letters with the STOP-Bang questionnaire results to the patient's primary physician. The results of the study impress the need for STOP-Bang OSA screening on admission from the emergency department and routine in-patient admissions. A CERNER @ EMR redesign to improve capture of intra-procedure documentation warrants consideration.

\section{Conclusion}

In answer to the question, to what extent do the STOP-Bang score variables reliably predict airway complications in conscious sedation procedures, select independent variables were found to be predictive of airway compromise and obstruction. Valuable insight was gained that can be used to improve quality processes within the hospital, specifically around patient safety during conscious sedation procedures. The study demonstrated that nurse-administered conscious sedation for a select population of patients is safe when in a monitored environment with personnel trained in conscious sedation and can rescue when deeper-than-intended states of sedation occur.

Independent variables that were significantly significant included increase in BMI and STOP-Bang scores of 3 or greater. Outcome variables that correlated to an increased risk of airway complications were a change in heart rate greater than $10 \%$ from baseline, development of hypoventilation as evidenced by abnormal $\mathrm{ETCO}_{2}$, apnea, a drop in $\mathrm{SpO}_{2}$ indicating hypoxia, and the need for tactile or verbal stimulation to relieve airway obstruction. The most likely explanation for this seems to be that as BMI increases and STOP-Bang scores increase above 3 , there is a greater risk of airway compromise or obstruction. The BMI is a verifiable objective variable and was statistically significant by point increase when correlated to dependent outcome variables. 
With these findings, proactive safety measures can be instituted for additional airway management for identified patients at risk. This information has application in the clinical consideration of monitoring protocols, medication administration, equipment availability, and staffing for patients with a high probability for airway obstruction. 
REFERENCES 


\section{REFERENCES}

Abdullah, H. R., Chung, F. (2014). Perioperative management of obstructive sleep apnea. Current Anesthesiology Reports, 4(1), 19-27.

Adams, L., Butas, S., Spurlock, D. (2015). Capnography $\left(\mathrm{ETCO}_{2}\right)$, respiratory depression and nursing interventions in moderately sedated adults undergoing transesophageal echocardiography (TEE). Journal of Perianesthesia Nursing, 30(1), 14-22.

American Academy of Sleep Medicine. (2016). Frost \& Sullivan: Hidden health crisis costing America billions. Underdiagnosing and undertreating obstructive sleep apnea draining healthcare system. Retrieved from http://www.aasmnet.org/sleep-apnea-economic-impact. aspx

Aurora, R., Collop, N., Jacobowitz, O., Thomas, S., Quan, S., \& Aronsky, A. (2015). Quality measures for the care of adult patients with obstructive sleep apnea. Journal of Clinical Sleep Medicine, 11(3), 357-383.

Carvalho, B., Hsia, J., \& Capasso, R. (2012). Surgical therapy of obstructive sleep apnea: A review. Neurotherapeutics, 9(4), 710-716. http://doi.org/10.1007/s13311-012-0141-x

Centers for Disease Control and Prevention. (2017). Adult Body Mass Index. Retrieved from https://www.cdc.gov/obesity/adult/defining.html 
Choi, J. K., Hur, Y. K., Lee, J. M., \& Clark, G. T. (2010). Effects of mandibular advancement on upper airway dimension and collapsibility in patients with obstructive sleep apnea using dynamic airway imaging during sleep. Oral Surg Oral Med Oral Pathol Oral Radiol Endod, 109, 712-719.

Chung, F. F., Abdullah, H. R., Liao, P. (2016). STOP-Bang Questionnaire: A practical approach to screen of obstructive sleep apnea. Chest, 149(3), 631638. https://doi:10.1378/chest.15-0903

Chung, F. F., Subramanyam, R., Liao, P., Sasaki, E., Shairo, C., \& Sun, Y., (2012). High STOP-Bang score indicates a high probability of obstructive sleep apnoea. British Journal of Anaesthesia, 108(5), 768-775.

Doshi, V., Walia, R., Parker, C., Awab, A., Jones, K., \& Aston, C. (2015), STOP-BANG questionnaire as a screening tool for diagnosis of obstructive sleep apnea by unattended portable monitoring sleep study, Chest, 148(4), 1039A.

Douglas, J. A., Chai-Coetzer, C. L., Mcevoy, D., Naughton, M. T., Neill, A. M., Rochford, P. . . W Worsnop, C. (2017). Guidelines for sleep studies in adults a position statement of the Australasian Sleep Association. Sleep Medicine, 36(S1), S2-S22.

Early, D., Lightdale, J., Vargo, J., Acosta, R., Chandrasekhara, V., Chathadi, K., . . . Dewitt, J. (2018). Guidelines for sedation and anesthesia in GI endoscopy. Gastrointestinal Endoscopy, 87(2), 327-337. 
Fanari, Z., Mohammed, A. A., Bathina, J. D., Hodges, D. T., Doorey, K., Gagliano, N., ... Doorey, A. J. (2018). Inadequacy of pulse oximetry in the catheterization laboratory. An exploratory study monitoring respiratory status using arterial blood gases during cardiac catheterization with conscious sedation. Cardiovascular Revascularization Medicine. Retrieved from https://doi.org/10.1016/j.carrev.2018.07.027

Fawcett, J. (2018). Using theory in evidence-based advanced nursing practice. In J. B. Butts, \& K. L. Rich (Eds.), Philosophies and theories for advanced nursing practice (pp. 485-518). Burlington, MA: Jones \& Bartlett Learning.

Gross, J., Bailey, P., Connis, R., Cote, C., Davis, F., Epstein, B., . . Zuccaro, G. (2002). Practice guidelines for sedation and analgesia by nonanesthesiologists - An updated report by the American Society of Anesthesiologists task force on sedation and analgesia by nonanesthesiologists. Anesthesiology, 96(4), 1004-1017.

Junna, M. R., Selin, B. J., \& Morgenthaler, T. I. (2013). Medical sedation and sleep apnea. Sleep Med Clin 8, 43-58. Retrieved from http://dx.doi.org/10.1016/j.jsmc.2012.11.012

Knapp, H. (2017). Practical statistics for nursing using SPSS®. Thousand Oaks, CA: Sage Publication, Inc. 
Mahmoud, H., Sallma, S., \& Mohammad, A. (2014). Validation of the Epworth Sleepiness Scale, Berlin, STOP-Bang Questionnaires and American Society of Anesthesiologists checklist as screening tools for obstructive sleep apnea in patients with chronic obstructive pulmonary disease, asthma, and cardiovascular diseases. Chest, 146(4), 944A.

Nagappa M, Liao P, Wong J, Auckley, Ramachandran, Memtsoudis,.... Chung (2015). Validation of the STOP-Bang questionnaire as a screening tool for obstructive sleep apnea among different populations: A systematic review and meta-analysis. PloS ONE.10(12):e0143697.

Doi:10.1371/journal.pone.0143697.

National Institute of Health, National Heart, Lung, Blood Institute (NIH NHLB). (2010). NIH study defines ideal body mass index. Retrieved from https://www.nih.gov/news-events/news-releases/nih-study-identifies-idealbody-mass-index

Nilsen, P. (2015). Making sense of implementation theories, models and frameworks. Implementation Science, 10(53), 1-13. Retrieved from https://www.ncbi.nlm.nih.gov/pmc/articles/PMC4406164/pdf/13012_2015_ Article_242.pdf

Nishadh, M. J., Ameer, K. A., \& Arjun, P. (2017). The accuracy of the STOPBang questionnaire in the identification of obstructive sleep apnoea (OSA) with polysomnography as the gold standard in adult patients with symptoms of sleep disordered breathing in a tertiary care centre in South India. Sleep Medicine, 40, E144-E145. 
Peppard, P., \& Hagen, E. (2017). The last 25 years of obstructive sleep apnea epidemiology—and the next 25? American Journal of Respiratory and Critical Care Medicine, 197(3), 310-312.

Sankar, A., Johnson, S. R., Beattie, W. S., Tait, G., \& Wijeysundera, D. N., (2014). Reliability of the American Society of Anesthesiologist physical status scale in clinical practice. British Journal of Anaesthesia, 113(3), 424432.

Toshniwal, G., Mckelvey, G. M., \& Wang, H. (2014). STOP-Bang and prediction of difficult airway in obese patients. Journal of Clinical Anesthesia, 26(5), 360-367.

University Health Network. (2012). STOP-Bang Questionnaire. Retrieved from http://www.stopbang.ca/osa/screening.php

Weaver, T. E., Sawyer, A. (2010). Adherence to continuous positive airway pressure treatment for obstructive sleep apnea: Implications for future interventions. The Indian Journal of Medical Research, 131, 245-258.

White, S., Spruce, L. (2015). Perioperative nursing leaders implement clinical practice guidelines using the Iowa Model of Evidence-Based Practice. AORN Journal, 102(1), 50-59.

Young T., Peppard P.E., \& Gottlieb D.J. (2002). Epidemiology of obstructive sleep apnea: A population health perspective. Am J Respir Crit Care Med, 165: 1217-1239. 
APPENDICES 
APPENDIX A: PARTICIPANT AND ORGANIZATIONAL CHARACTERISTICS 
Participant and organizational characteristics.

\begin{tabular}{|c|c|c|c|c|}
\hline \multicolumn{5}{|c|}{ Predictor Variables } \\
\hline Variable & $\begin{array}{c}\text { Type of } \\
\text { variable/level of } \\
\text { measure }\end{array}$ & Description & Value & $\begin{array}{l}\text { Min. } \\
\mathrm{n}^{*}\end{array}$ \\
\hline Age & $\begin{array}{l}\text { Continuous - } \\
\text { ratio }\end{array}$ & Age in years & $>=18$ & 10 \\
\hline Sex & $\begin{array}{l}\text { Categorical - } \\
\text { nominal }\end{array}$ & Gender & male/female & 10 \\
\hline Gender & $\begin{array}{l}\text { Categorical - } \\
\text { nominal }\end{array}$ & $\begin{array}{l}\text { GENDER: } \\
\text { Male? }\end{array}$ & Yes/No & N/A \\
\hline Snoring & $\begin{array}{l}\text { Categorical - } \\
\text { nominal }\end{array}$ & $\begin{array}{l}\text { Do you SNORE } \\
\text { loudly (louder } \\
\text { than talking or } \\
\text { loud enough to } \\
\text { be heard } \\
\text { through closed } \\
\text { doors)? }\end{array}$ & Yes/No & 10 \\
\hline Tired & $\begin{array}{l}\text { Categorical - } \\
\text { nominal }\end{array}$ & $\begin{array}{l}\text { Do you often } \\
\text { feel TIRED, } \\
\text { fatigued, or } \\
\text { sleepy during } \\
\text { daytime? }\end{array}$ & Yes/No & 10 \\
\hline Observed & $\begin{array}{l}\text { Categorical - } \\
\text { nominal }\end{array}$ & $\begin{array}{l}\text { Has anyone ever } \\
\text { observed you } \\
\text { stop breathing } \\
\text { during your } \\
\text { sleep? }\end{array}$ & Yes/No & 10 \\
\hline Pressure & $\begin{array}{l}\text { Categorical - } \\
\text { nominal }\end{array}$ & $\begin{array}{l}\text { Do you have or } \\
\text { are you being } \\
\text { treated for high } \\
\text { blood } \\
\text { PRESSURE? }\end{array}$ & Yes/No & 10 \\
\hline
\end{tabular}




\begin{tabular}{|c|c|c|c|c|}
\hline Height & $\begin{array}{l}\text { Continuous - } \\
\text { ratio }\end{array}$ & $\begin{array}{l}\text { Measured at } \\
\text { time of } \\
\text { procedure }\end{array}$ & $\begin{array}{l}\text { Recorded height in } \\
\text { centimeters }\end{array}$ & 10 \\
\hline Weight & $\begin{array}{l}\text { Continuous - } \\
\text { ratio }\end{array}$ & $\begin{array}{l}\text { Measured at } \\
\text { time of } \\
\text { procedure }\end{array}$ & $\begin{array}{l}\text { Recorded weight in } \\
\text { pounds }\end{array}$ & 10 \\
\hline BMI - Calc & $\begin{array}{l}\text { Continuous - } \\
\text { ratio }\end{array}$ & $\begin{array}{l}\text { Calculated BMI } \\
\mathrm{kg} / \mathrm{m}^{2} \text { based on } \\
\text { Height } / \text { weight } \\
\text { at time of } \\
\text { procedure }\end{array}$ & Recorded as BMI & 10 \\
\hline BMI & $\begin{array}{l}\text { Categorical - } \\
\text { nominal }\end{array}$ & $\begin{array}{l}\text { BMI more than } \\
35 \mathrm{~kg} / \mathrm{m}^{2} ?\end{array}$ & Yes/No & 10 \\
\hline Age $>50$ & $\begin{array}{l}\text { Categorical- } \\
\text { nominal }\end{array}$ & $\begin{array}{l}\text { AGE over } 50 \\
\text { years old? }\end{array}$ & Yes/No & 10 \\
\hline Neck & $\begin{array}{l}\text { Categorical- } \\
\text { nominal }\end{array}$ & $\begin{array}{l}\text { NECK female: } \\
\text { circumference }> \\
16 \text { inches } \\
(40 \mathrm{~cm}) \text { ? Male: } \\
\text { Greater than } 17 \\
\text { inches }(42 \mathrm{~cm}) \text { ? }\end{array}$ & Yes/No & 10 \\
\hline Total Score & $\begin{array}{l}\text { Continuous- } \\
\text { ratio }\end{array}$ & $\begin{array}{l}\text { Total calculated } \\
\text { STOP-Bang } \\
\text { score }\end{array}$ & $\begin{array}{l}\text { Recorded as Total } \\
\text { score }\end{array}$ & 10 \\
\hline $\begin{array}{l}\text { High risk of } \\
\text { OSA }\end{array}$ & $\begin{array}{l}\text { Categorical- } \\
\text { nominal }\end{array}$ & $\begin{array}{l}\text { High risk of } \\
\text { OSA: Yes } 5 \text { - } 8\end{array}$ & Yes/No & 10 \\
\hline $\begin{array}{l}\text { Intermediate } \\
\text { risk of OSA }\end{array}$ & $\begin{array}{l}\text { Categorical- } \\
\text { nominal }\end{array}$ & $\begin{array}{l}\text { Intermediate } \\
\text { risk of OSA: } \\
\text { Yes } 3 \text { - } 4\end{array}$ & Yes/No & 10 \\
\hline $\begin{array}{l}\text { Low risk of } \\
\text { OSA }\end{array}$ & $\begin{array}{l}\text { Categorical- } \\
\text { nominal }\end{array}$ & $\begin{array}{l}\text { Low risk of } \\
\text { OSA: Yes } 0 \text { - } 2\end{array}$ & Yes/No & 10 \\
\hline $\begin{array}{l}\text { Fentanyl/other } \\
\text { narcotic }\end{array}$ & $\begin{array}{l}\text { Continuous } \\
\text { ratio }\end{array}$ & $\begin{array}{l}\text { Total dose used } \\
\text { during }\end{array}$ & $\begin{array}{l}\text { Total amount } \\
\text { recorded }\end{array}$ & 10 \\
\hline
\end{tabular}




\begin{tabular}{|l|l|l|l|l|}
\hline analgesics & & procedure & & \\
\hline Midazolam & $\begin{array}{l}\text { Continuous } \\
\text { ratio }\end{array}$ & $\begin{array}{l}\text { Total } \\
\text { milligrams of } \\
\text { Midazolam used } \\
\text { during } \\
\text { procedure }\end{array}$ & $\begin{array}{l}\text { Total amount } \\
\text { recorded }\end{array}$ & 10 \\
\hline Total n & & & & 180 \\
\hline
\end{tabular}

(Aurora et al., 2015; Abdullah et al., 2014; Choi et al., 2010)

*Minimum sample size (n) required to run logistic regression analysis:

For each continuous predictor variables: 10 
APPENDIX B: PATIENT DATA COLLECTION TOOL 
Chart Review Code \#

Identifying Predictors of Airway Complications in Conscious Sedation Procedures Data Collection Tool

\begin{tabular}{|c|c|c|c|c|}
\hline Code & Variable & Description & Result & $\begin{array}{l}\text { Location in } \\
\text { EMR }\end{array}$ \\
\hline Age & Age & Age in years & & Surginet \\
\hline Sex & Sex & Male/Female & & Surginet \\
\hline Male & Gender: Male & $\mathrm{Y} / \mathrm{N}$ & & Surginet \\
\hline Snor & Snoring: History of & $\mathrm{Y} / \mathrm{N}$ & & Surginet \\
\hline Tire & Tired: History chronic & $\mathrm{Y} / \mathrm{N}$ & & Surginet \\
\hline $\mathrm{BP}$ & Pressure: Hx HTN & $\mathrm{Y} / \mathrm{N}$ & & Surginet \\
\hline $\mathrm{Ht}$ & Height & $\begin{array}{l}\text { Recorded } \\
\text { height in } \\
\text { centimeters }\end{array}$ & & $\begin{array}{l}\text { Surginet } \\
\text { /Patient } \\
\text { Questionnaire }\end{array}$ \\
\hline $\mathrm{Wt}$ & Weight & $\begin{array}{l}\text { Recorded } \\
\text { weight in } \\
\text { pounds }\end{array}$ & & $\begin{array}{l}\text { Surginet } \\
\text { /Patient } \\
\text { Questionnaire }\end{array}$ \\
\hline BMI-C & BMI-Calc & $\begin{array}{l}\text { Numerical } \\
\text { BMI }\end{array}$ & & Surginet \\
\hline BMI\# & $\mathrm{BMI}>35 \mathrm{~kg} / \mathrm{m}$ & $\mathrm{Y} / \mathrm{N}$ & & Surginet \\
\hline Neck & Neck > 16" & $\mathrm{Y} / \mathrm{N}$ & & Surginet \\
\hline SBTot & Total STOP-Bang Score & $\begin{array}{l}\text { Numerical } \\
\text { score } 1-8\end{array}$ & & Surginet \\
\hline HOSA & High Risk OSA (score 5-8) & $\mathrm{Y} / \mathrm{N}$ & & Surginet \\
\hline
\end{tabular}




\begin{tabular}{|c|c|c|c|}
\hline IOSA & $\begin{array}{l}\text { Intermediate risk of OSA } \\
\text { (score 3-4) }\end{array}$ & $\mathrm{Y} / \mathrm{N}$ & Surginet \\
\hline LOSA & $\begin{array}{l}\text { Low Risk of OSA (score 0- } \\
\text { 2) }\end{array}$ & $\mathrm{Y} / \mathrm{N}$ & Surginet \\
\hline Fent & $\begin{array}{l}\text { Fentanyl total dose in } \\
\text { microgram }\end{array}$ & $\begin{array}{l}\text { Numerical } \\
\text { dose }\end{array}$ & Surginet \\
\hline Midz & $\begin{array}{l}\text { Midazolam total dose in } \\
\text { milligrams }\end{array}$ & $\begin{array}{l}\text { Numerical } \\
\text { dose }\end{array}$ & Surginet \\
\hline Demerol & $\begin{array}{l}\text { Demerol total dose in } \\
\text { milligrams }\end{array}$ & $\begin{array}{l}\text { Numerical } \\
\text { dose }\end{array}$ & Surginet \\
\hline \multicolumn{2}{|c|}{ Patient observations during procedure } & $\begin{array}{l}\mathrm{Y}=\text { present } \\
\mathrm{N}=\text { Absent }\end{array}$ & \\
\hline Snor & Audible snoring or stridor & $\mathrm{Y} / \mathrm{N}$ & Surginet \\
\hline HR & $\begin{array}{l}\text { Change in heart rate greater } \\
\text { than } 10 \% \text { from baseline }\end{array}$ & $\mathrm{Y} / \mathrm{N}$ & Surginet \\
\hline Arr & Development of arrhythmia & $\mathrm{Y} / \mathrm{N}$ & Surginet \\
\hline $\mathrm{ETCO}_{2}$ & $\begin{array}{l}\text { Abnormal End Tidal } \mathrm{CO}_{2} \\
\text { value }<35 \text { mmHG or }>45 \\
\text { mmHg }\end{array}$ & $\mathrm{Y} / \mathrm{N}$ & Surginet \\
\hline $\mathrm{SpO}_{2}$ & $\begin{array}{l}\text { Drop in } \mathrm{SpO}_{2} \text { value more } \\
\text { than } 3 \% \text { from baseline }\end{array}$ & $\mathrm{Y} / \mathrm{N}$ & Surginet \\
\hline Apnea & $\begin{array}{l}\text { Periods of apnea greater } \\
\text { than } 8 \text { secs }\end{array}$ & $\mathrm{Y} / \mathrm{N}$ & Surginet \\
\hline
\end{tabular}




\begin{tabular}{|l|l|l|l|l|}
\hline \multicolumn{3}{|l|}{ Basic Airway Maneuvers } & & \\
\hline & $\begin{array}{l}\text { Side-lying recovery position } \\
\text { (for purpose of airway - not } \\
\text { Side }\end{array}$ & & & Surginet \\
\hline JawT & Jaw-Thrust & Y/N & Surginet \\
\hline HTCL & Head tilt-Chin Lift & Y/N & Surginet \\
\hline Arobs & $\begin{array}{l}\text { Arousal-relieved airway } \\
\text { obstruction }\end{array}$ & & \\
\hline Advanced & Airway Maneuvers & Y/N & Surginet \\
\hline Suct & Airway Suction & Surginet \\
\hline & Oral or nasal pharyngeal & & \\
\hline OPA & $\begin{array}{l}\text { airway placement (OPA; } \\
\text { NPA) }\end{array}$ & & & \\
\hline BVV & Bag-valve ventilation & Y/N & Surginet \\
\hline ET/LMA & $\begin{array}{l}\text { (ET/LMA) } \\
\text { Continuous positive airway } \\
\text { pressure (CPAP) or (Bipap) }\end{array}$ & Y/N & Surginet \\
\hline Advanced airway placement & & & \\
\hline
\end{tabular}


APPENDIX C: IRB APPROVAL 


\section{ว Dignity Health.}

Federal Wide Assurance (FWA) $=00001499$ Dignity Health IORGDOD 1540

Date:

IRB:

To:

IRB \#:

Study Title:

IRB Submission:

Protocol Version Date:

Reference \#:

Review Cycle:

Approval Expiration Date:

IRB Review Type:

IRB Review Date:

IRB Decision:
February 13, 2019

Dignity Health CAVNV IRB \#00006573

3400 Data Drive

Rancho Cordova, CA 95870

Rosemary Bray

CANV DHIRB-2018-363

IDENTIFYING PREDICTORS OF AIRWAY COMPLICATIONS IN CONSCIOUS SEDATION PROCEDURES

Submission Response for Initial Review Submission Form

$01 / 07 / 2018$

026278

12 Months

$02 / 12 / 2020$

Exempt

$02 / 13 / 2018$

Approved

The Institutional Review Board (IRB) reviewed and approved your new protocol submission under exemption category \#4 and is exempt from further IRB review.

Code of Federal Regulations 45 CFR 46.101 (b) (4): Research involving the collection or study of existing data, documents, records, pathological specimens, or diagnostic specimens, if these sources are publicly available or if the information is recorded by the investigator in such a manner that participants cannot be identified, directly or through identifiers linked to the subject. To qualify for this exemption, the data, documents, records, or specimens must be in existence before the project begins.

A waiver of informed consent/authorization and HIPAA exemption form have been reviewed and approved. All data obtained will be recorded without any identifiable information.

Please be sure you have received a final administrative approval letter prior to implementing your study.

The guidelines established by the Dignity Health CAINV IRB require that as Principal Investigator you are responsible for the following:

- Adherence to applicable Federal regulations, Dignity Health policy and the policies of this Institutional Review Board.

- Reporting of any proposed changes in the protocol procedures to the IRB for approval prior to implementation. (Please note that changes made in the protocol procedures and/or methods may affect the exemption status of this study)

The IRB and Dignity Health maintains the authority to terminate or suspend approval of research that is not being conducted in accordance with the requirements stated above and/or research that has been associated with unexpected serious harm to participants.

If you have any questions or need further assistance please contact the Dignity Health CAINV IRB at 415-750-5854 or by e-mail to Russell.Stolp@DignityHealth.org-

Dignity Health is organized and operates according to its Federal Wide Assurance with the Department of Health and Human Services (DHHS) omce of Human Research Protections (OHRP). Dignity Health IRBs operate in complance with the code of (Revised 04/01/2016) 
Title: Predictors Airway Complications

Reference $\# 026278$

Page 2 of 2

Sincerely.

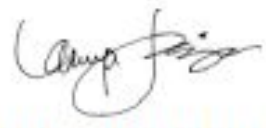

Lamya Jarjour, MD

IRB Co-Chair
$2 P .42$.

Jeffrey Braff, DrPH

IRB Co-Chair

(This has been electronically signed)

Appendix 1

\begin{tabular}{|c|c|c|}
\hline \multicolumn{3}{|l|}{ Submission Components } \\
\hline Form Name & Version & Outcome \\
\hline $\begin{array}{l}\text { Review Response Submission } \\
\text { Form }\end{array}$ & Version 1.0 & Approved \\
\hline $\begin{array}{l}\text { Initial Review Submission } \\
\text { Form }\end{array}$ & Version 1.0 & Approved \\
\hline $\begin{array}{l}\text { Dignity Health Internal IRB } \\
\text { Application }\end{array}$ & Version 1.1 & Approved \\
\hline
\end{tabular}

\begin{tabular}{|l|l|l|l|}
\hline Study Document & Version \# & Version Date & Outcome \\
\hline Title & Version 2.0 & $01 / 07 / 2019$ & Approved \\
\hline FULL PROTOCOL: & & \\
BRAY_Rose & & & \\
DENTIFYING & & & \\
PREDICTORS OF \\
AIRWAY \\
COMPLICATIONS IN \\
CONSCIOUS \\
SEDATION
\end{tabular}

Dignity Health is organized and operates according to its Federal Wide Assurance with the Department of Health and Human Services (DHHS) Oflce of Human Research Protections (OHRP). Dignity Health IRBs operate in complance with the Code of (Revised 04/01/2016) Federal Regulations (CFR) Including 45 CFR 46, 21 CFR 56 and 21 CFR 11. 